\title{
Anomalous Seismic Amplitudes Measured in the Los Angeles Basin Interpreted as a Basin-Edge Diffraction Catastrophe
}

\author{
by Allen L. Husker, Monica D. Kohler, and Paul M. Davis
}

\begin{abstract}
The Los Angeles Basin Passive Seismic Experiment (LABPSE) involved the installation of an array of 18 seismic stations along a line crossing the Los Angeles basin from the foothills of the San Gabriel Mountains through the Puente Hills to the coast. At 3-5 km spacing between stations the array has much higher resolution than the permanent network of stations in southern California. This resolution was found to be important for analyzing the factors that govern the amplitude variation across the basin. We inverted spectra of $P$ - and $S$-body-wave seismograms from local earthquakes $\left(M_{\mathrm{L}}\right.$ 2.1-4.8) for site effects, attenuation, and corner frequency factor using a standard model that assumes geometric spreading varying as inverse distance, exponential attenuation, and an $\omega^{2}$ source model. The $S$-wave attenuation was separable into basin and bedrock contributions. In addition to the body-wave analysis, $S$-wave coda were analyzed for coda $Q$ and coda-determined site effects. We find $S$ wave $Q\left(Q_{S}\right)$ in bedrock is higher than in the basin. High-frequency $Q_{S}$ is higher than low-frequency $Q_{S}$. Coda $Q\left(Q_{c}\right)$ is higher than $Q_{S}$. $P$-wave $Q\left(Q_{P}\right)$ was not separable into basement and bedrock values, so we determined an average value only. The corner frequencies for $P$ and $S$ waves were found to be nearly the same. The standard model fit over $97 \%$ of the $S$-wave data, but data from six clustered events incident along the basin edge within a restricted range of incidence and azimuth angles generated anomalous amplitudes of up to a factor of 5 higher than predicted. We test whether such basin-edge focusing might be modeled by catastrophe theory. After ruling out site, attenuation, and radiation effects, we conclude a caustic modeled as a diffraction catastrophe could explain both the frequency and spatial dependence of the anomalous variation.
\end{abstract}

\section{Introduction}

The standard model for amplitudes of seismic waves from local earthquakes includes the omega-squared representation for the source, a site-factor term, geometric spreading, and attenuation effects (Aki, 1967; Brune, 1970). However, when multipathing or focusing occurs, such as at a basin edge, the standard model can significantly underestimate amplitudes that, in the infinite frequency limit, are better described by caustics or more generally by catastrophes (Berry, 1976; Rial, 1984; Nye, 1985). Unexpectedly high amplitudes were observed in a seismic array installed in Santa Monica, California, in a region of extreme damage from the 1994 Northridge earthquake, suggesting that the (Los Angeles) basin-edge there caused focusing of seismic waves from the focal region of the event (Gao et al., 1996). A similar observation had been made by Rial (1984) who showed a good correlation between the damage pattern from the 1967 Caracas, Venezuela, earthquake and caustic locations calculated for the Caracas basin. We report here another observation of focused seismic waves along the Los
Angeles basin edge in an array located $40 \mathrm{~km}$ to the east of Santa Monica. However, the geometry is markedly different in that the focused waves are incident along the basin edge rather than normal to it as in Santa Monica, or beneath the basin as in Caracas. In each case, focusing of seismic waves is plausibly explained by velocity gradients located in different parts of the geology such as the convex low-velocity structures formed by basin sedimentary rock enclosed in bedrock.

To identify caustics it is necessary to examine other factors that may affect seismic amplitudes differentially, such as site effects, attenuation, and radiation pattern. Attenuation is separated into its near-station basin and basement contributions to more accurately account for its effect (Hough et al., 1988). We find that the radiation pattern is not evident in the spectral amplitudes we measured, possibly because of scattered secondary arrivals. We estimate site effects using relative coda amplitudes and find they are at a maximum where the basins are deepest, but they do not ex- 
plain basin-edge effects. We conclude that the anomalous arrivals at the Los Angeles basin edge are due to seismic focusing.

\section{Data}

The data examined here consist of spectral amplitudes of seismograms recorded by the Los Angeles Basin Passive Seismic Experiment (LABPSE) (Kohler et al., 2000). LABPSE ran from March to November 1997. The array comprised 18 closely spaced stations that recorded local and regional earthquakes and teleseisms. The seismographs consisted of Reftek recorders coupled to three-component $1-\mathrm{Hz}$ Mark Products L4C geophones. The array stretched north to south from the southern edge of the San Gabriel Mountains across the San Gabriel Basin, the Puente Hills, the Los Angeles Basin, to Seal Beach (Fig. 1) with seismic stations spaced $3-5 \mathrm{~km}$ apart. The total length of the array was approximately $60 \mathrm{~km}$.

More than 2000 events with $M_{\mathrm{L}}>2$ were recorded and cataloged during the experiment. Events were used in this study if the direct $P$ or direct $S$ wave was clearly distinguishable above the noise on at least half of the stations. We chose to study the $40 P$-wave and $43 S$-wave events that matched the criteria best. They ranged in magnitude from 2.1 to 4.8 (Table 1). Locations of the events and the stations are shown in Figure 1. Event 19 occurred 2 sec after event 18 (Fig. 2) and is not listed in the Southern California Seismic Network (SCSN) catalog. We put its location in the same place as event 18 because both $P$ and $S$ waves at all stations occur $2 \mathrm{sec}$ after those waves for event 18 and the waveforms look quite similar.

The data were corrected for (L4C) instrument response and converted to a flat velocity spectrum between 1 and 10 Hz. The seismograms were converted to spectral amplitudes by taking an fast Fourier transform (FFT) of a 2-sec window centered on the beginning of the first $P$ wave and a 4 -sec window centered on the beginning of the $S$ wave. The FFTs were broken into two frequency bands for the inversion: 1$5 \mathrm{~Hz}$ and $5-10 \mathrm{~Hz}$. Average spectral amplitudes were used in each band to examine amplitude variation with frequency.

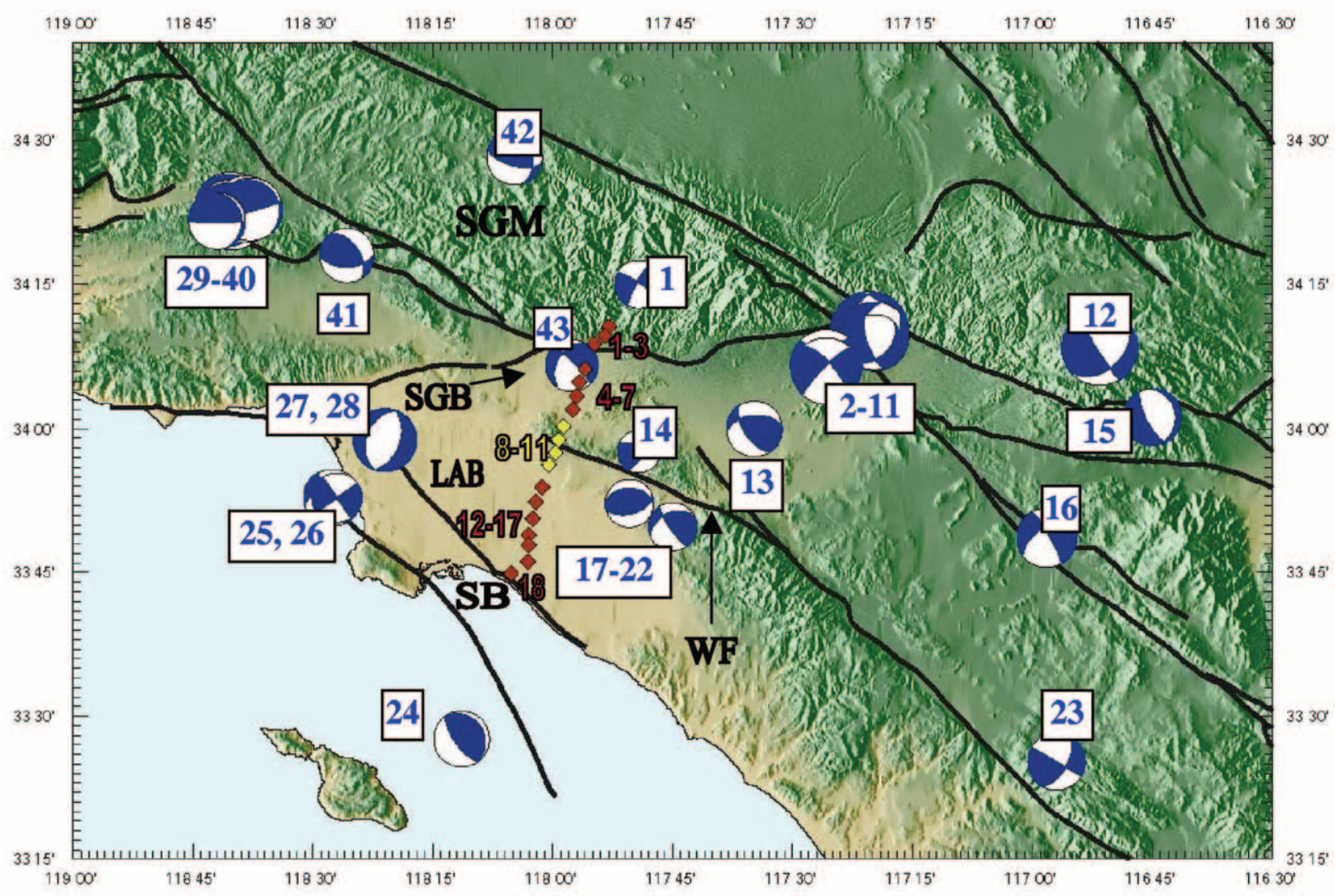

Figure 1. LABPSE seismic stations are red (noncaustic) and yellow (caustic) diamonds. Events used in this study are displayed as focal mechanisms. Those events that had no focal mechanism available are located within clusters of events with focal mechanisms. Event numbering goes as increasing back azimuth from station 11. LAB, Los Angeles basin; SB, Seal Beach; SGB, San Gabriel Basin; SGM, San Gabriel Mountains; WF, Whittier Fault. 
Table 1

Events Used in Study

\begin{tabular}{|c|c|c|c|c|c|c|c|}
\hline \multirow{2}{*}{$\begin{array}{c}\text { Event } \\
\text { No. }\end{array}$} & \multirow[b]{2}{*}{ Latitude } & \multirow[b]{2}{*}{ Longitude } & \multirow[b]{2}{*}{$M_{\mathrm{L}}$} & \multirow[b]{2}{*}{ Depth } & \multirow{2}{*}{$\begin{array}{c}\text { UTC Time } \\
\text { (yy/mm/dd, h:m:s) }\end{array}$} & \multicolumn{2}{|c|}{$E_{j}^{*}$} \\
\hline & & & & & & $P$ wave & $S$ w: \\
\hline $1^{\dagger}$ & 34.25 & 117.82 & 2.6 & 7.9 & 45 & & 0.07 \\
\hline 2 & 34.17 & & 4.2 & 10 & $97 / 0$ & 3.55 & \\
\hline 3 & 34.17 & .34 & 2.7 & 9.7 & $97 / 06 / 28,2$ & & \\
\hline 4 & 34.16 & 117.33 & 3.5 & 10.3 & $97 / 07 / 12,18: 05: 40$ & 0.82 & \\
\hline 5 & 34.16 & 117.33 & 3.7 & 9.8 & $97 / 07 / 26,10: 24: 16$ & 1.31 & 1.6 \\
\hline 6 & 34.12 & -117.45 & 2.3 & 3.2 & $97 / 07$ & 0.06 & 0.09 \\
\hline 7 & 34.15 & -117.33 & 2.7 & 8.9 & 97/07 & 0.17 & 0.22 \\
\hline 8 & 34.15 & -117.33 & 2.8 & 10.1 & $97 / 07$ & 0.21 & 0.28 \\
\hline 9 & & -117.33 & 3 & 6.2 & $97 / 0$ & & 0.42 \\
\hline 10 & & & 3.9 & 3 & 971 & & 1.90 \\
\hline 11 & 34.1 & & 3.6 & 4.4 & $97 / 1$ & & 1.05 \\
\hline 12 & & -11 & 4.1 & 10.2 & $97 /$ & & 10.48 \\
\hline 13 & 34 & 8 & 3 & 2.7 & $97 / 03$ & & 2. \\
\hline 14 & & & 2.3 & 12 & 97 & & .0 \\
\hline 15 & & & 3.1 & 13.3 & 97 & & .35 \\
\hline 16 & & & 3.2 & 13 & & 1.15 & . \\
\hline $17^{\ddagger}$ & & & 2.6 & 4.7 & & 0.03 & 0.0 \\
\hline $18^{\dagger *}$ & 33.88 & 3 & 2.6 & 4.7 & $97 / 0$ & & م 0 \\
\hline 19 & 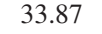 & & 4 & 6.1 & $97 / 0$ & 0.02 & 03 \\
\hline 20 & 33.87 & -11 & 2.6 & 6.2 & $97 / 07$ & 0.02 & 0.0 \\
\hline $21^{*}$ & 33.87 & -117 & 2 & 6 & $97 / 11 /$ & .01 & 0.02 \\
\hline 22 & 33 & -1 & 6 & 7.5 & & & 0.0 \\
\hline 23 & 33. & -116 & 3.1 & 11.6 & & & .20 \\
\hline 24 & & & 3 & & & & 0.19 \\
\hline 25 & 33 & & 2.7 & 11.9 & & & .13 \\
\hline 26 & 33 & & 1 & 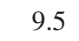 & 97 & 0.16 & 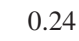 \\
\hline 27 & & & 3.4 & 4 & 97 & 0.23 & 0.4 \\
\hline $28^{+}$ & & O & 2.4 & 4.5 & 97 & 0.04 & 0 \\
\hline 29 & & - & 3.1 & 15.2 & & 0.60 & 0 \\
\hline 30 & 3 & -11 & 3.4 & 17 & & 1.18 & 1.2 \\
\hline 31 & & -118.67 & 3.8 & 15.2 & $97 / 0$ & 2.32 & 2.8 \\
\hline 32 & & -118 & 4 & 14.6 & $97 / 0$ & 3.64 & 4. \\
\hline 33 & & -118.65 & 3 & 14.8 & $5,11: 10$ & 0.47 & 0.5 \\
\hline 34 & & -1 & 2.7 & 14.6 & $97 / 04$ & 0.26 & 0.27 \\
\hline 35 & & & 3.1 & 15 & & & 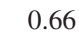 \\
\hline 36 & & & 2.0 & 14.0 & & & 0.5 \\
\hline 37 & & & 3.1 & 14 & $97 / C$ & 0.57 & 0. \\
\hline 38 & 34.38 & -118 & 3.6 & 13.8 & $97 / 04 / 27,11: 31: 20$ & 1.47 & 1.6 \\
\hline $39^{\dagger}$ & 34.38 & -118.63 & 2.7 & 14.7 & $97 / 04 / 27,12: 18: 53$ & & 0.2 \\
\hline 40 & 34.38 & -118.63 & 3.4 & 15.3 & $97 / 04$ & 1.02 & 1.1 \\
\hline 41 & 34.3 & -118 & 2.9 & 9.5 & $97 / 05 / 05,10: 30: 43$ & 0.20 & 0.2 \\
\hline 42 & 34.47 & -118.08 & 3 & 9.9 & 97/07/11, 06:40:23 & 0.19 & 0.30 \\
\hline 43 & 34.11 & -117.96 & 2.8 & 12.1 & $97 / 08 / 19,21: 37: 18$ & 0.02 & 0.05 \\
\hline
\end{tabular}

*The event parameters, $E_{j}$, have been normalized to the average of the $E_{j}$ for $P$ waves or $S$ waves to better observe relative values.

'Events not used in $P$-wave analysis because of a lack of strong signalto-noise ratio on at least half of the $P$ waves for those events.

${ }^{\ddagger}$ Events that have no focal mechanism available and not used in the focal mechanism inversion.

\section{Development of the Spectral Amplitude Model}

\section{Coda $Q$ and Site Factors}

To test if the anomalous variation is due to a site effect or focusing, it is necessary to have an independent estimate of site effects that can be determined from relative coda amplifications. Coda amplitudes near a specific site should be dominated by the local site conditions and will average out any azimuthal effects. Azimuthal averaging occurs because the coda are compared at extended times after the arrival of the direct waves. Then they are largely due to backscattering from velocity heterogeneities within the crust (e.g., Aki and Richards, 2003) generating omnidirectional arrivals at a given site. $S$-wave coda amplitudes at the $i$ th station for the jth earthquake are modeled as (Aki and Chouet, 1975)

$$
A_{i j}\left(t_{i j}\right)=\frac{A_{0 i j}}{t_{i j}} e^{-\omega\left(t_{i j}-t_{0}\right) / 2 Q_{C}},
$$

that is,

$$
\ln \left(A_{i j}\left(t_{i j}\right) t_{i j}\right)=a_{i j}+\left(t_{0}-t_{i j}\right) b,
$$

where $a_{i j}=\ln \left(A_{0 i j}\right)$ and $b=\omega / 2 Q_{C}$ were fit to the absolute values of the coda. $Q_{C}$ is coda $Q$ and $A_{i j}$ is noise-corrected spectral amplitudes measured over 10 contiguous $4-\mathrm{sec}$ windows starting at $t_{0}=80 \mathrm{sec}$ after the time of the rupture (e.g., Steck et al., 1989). The method of Steck et al. (1989) differs from ours by using a start time of twice the time from the earthquake to the first $S$-wave arrival at the station. We chose to measure the same time windows for all event and station combinations to have the same amount of geometrical spreading at each site.

Noise-corrected spectral amplitudes are given by

$$
A=\sqrt{\frac{\sum A_{C}^{2}-\sum A_{n}^{2}}{N}},
$$

where $\Sigma A_{C}^{2}$ is the summation of the amplitudes squared from the FFT over a 4-sec window from the coda for a given frequency range, $\Sigma A_{n}^{2}$ is the noise-squared summation taken over the first $4 \mathrm{sec}$ before the rupture in the same frequency range, and $N$ is the number of frequencies in the FFT. If $\Sigma A_{C}^{2}$ was less than 2.0 times $\Sigma A_{n}^{2}$ the data point was not used because of a presumed poor signal-to-noise ratio. The highfrequency $(5-10 \mathrm{~Hz})$ data in the tail of the coda $(+100 \mathrm{sec}$ after the rupture) had very few points that met the signal-tonoise ratio criterion. Therefore, only the low-frequency (1$5 \mathrm{~Hz}) A_{i j}$ was used for site terms in equation (2). The noisecorrected $A_{i j}$ was fit to equation (2) to determine $a_{i j}$ and $b$. An initial fit was used to determine the mean value of $b$, which in turn yielded $Q_{C}$. Values of $a_{i j}$ at each site were averaged to give $a_{i}$. The logarithms of the relative site factors were obtained from the differences in $a_{i}$. The resulting codaderived site factors are plotted in Figure 3.

\section{Standard Model: $S$ Waves}

The standard model for spectral amplitudes is based on the $\omega^{2}$ source (Aki, 1967; Brune, 1970) which, in general, has been found to fit spectra from local earthquakes (e.g., Abercrombie, 1995). We assume that geometrical spreading causes amplitudes to decay as inverse distance traveled and 


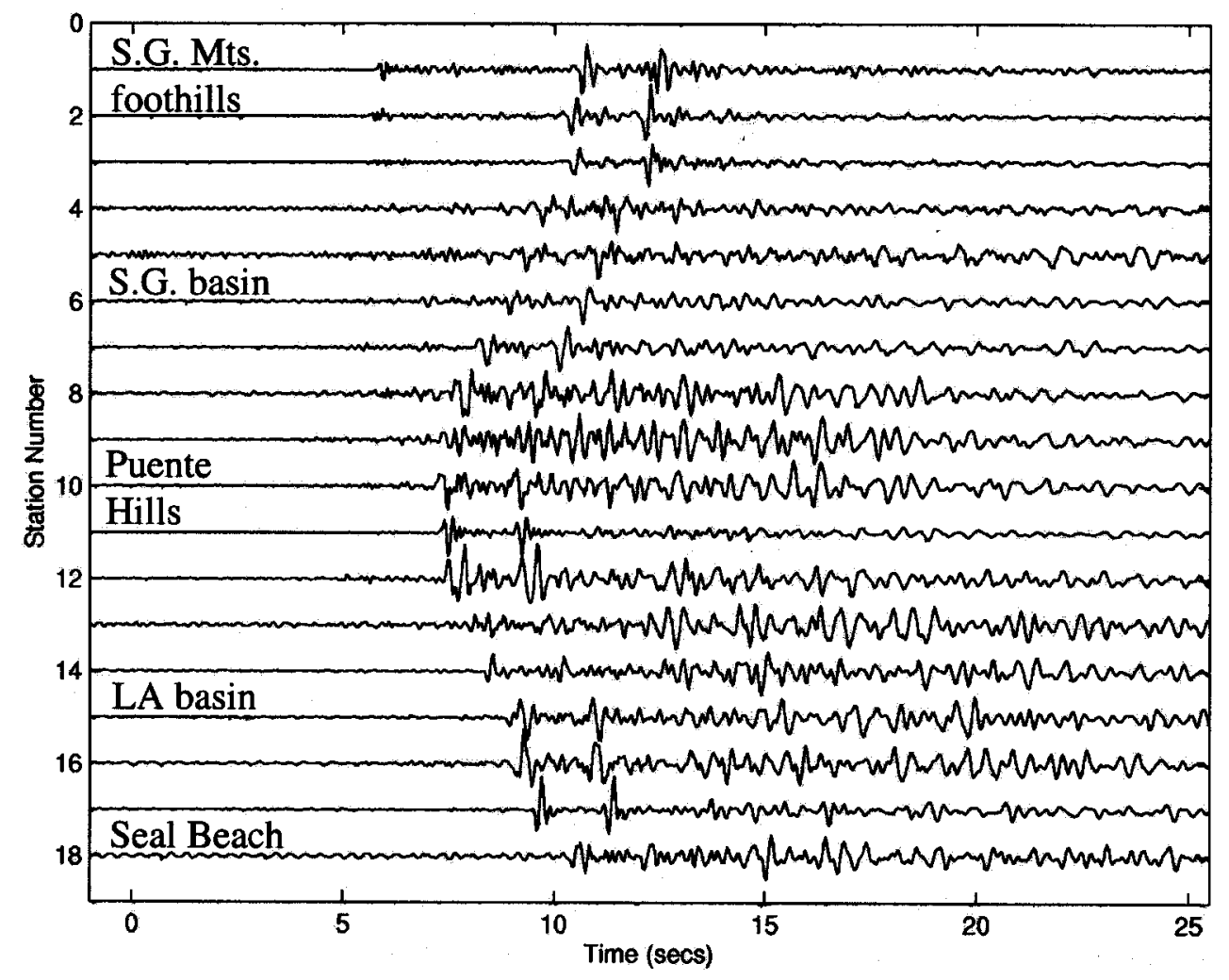

Figure 2. The north-south component of events 17 and 18, which occurred in the same location within about $2 \mathrm{sec}$ of each other. S.G Mts., San Gabriel Mountains; LA basin, Los Angeles.

that the distance traveled is proportional to travel time. Attenuation is separated into basin and bedrock paths and into the two different frequency components, with a different $Q$ value assigned to each. A nonlinear least-squares inversion was applied to the spectral amplitude data using

$A_{i j}(\omega)=S_{i} \frac{E_{j} \omega}{1+\left(\omega / \omega_{0 j}\right)^{2}} \frac{\exp \left(\sum_{l}^{2}-t_{i j l} \omega / 2 Q_{l}(\omega)\right)}{T_{i j}}$,

where $A_{i j}$ is the model value for the spectral amplitude at the $i$ th station for the $j$ th earthquake. $S_{i}$ is the site effect, $E_{j}$ is the event amplitude, $\omega$ is the mean angular frequency for each band, and $\omega_{0 j}$ is the corner angular frequency. The mean frequency of the two bands was set as the average of the band (i.e., for the $1-5 \mathrm{~Hz}$ band $\omega=2 \pi \times 3.3 \mathrm{~Hz}$, and for $5-10 \mathrm{~Hz} \omega=2 \pi \times 7.0 \mathrm{~Hz}$ ). $Q$ is the quality factor. The index $l=1$ or 2 denotes basin or bedrock, respectively. The $T_{i j}$ values are times between earthquake initiation and the first $S$-wave arrival. The total travel time is $T_{i j}=t_{i j 1}+$ $t_{i j 2}$, where $t_{i j 1}$ and $t_{i j 2}$ are the basin and bedrock travel times, respectively. Travel times were determined by ray tracing through a 1D linearized version of the Southern California Earthquake Center (SCEC) velocity model as discussed below.
Corner frequency, $\omega_{0}$, can be interpreted as the ratio of rupture velocity, $V_{R}$, to the fault length, $l_{j}$, multiplied by a constant, $\zeta$ (e.g., Stacey, 1992).

$$
\omega_{0 j}=\frac{\zeta V_{R}}{l_{j}}
$$

We assumed the rupture velocity is $90 \%$ of the shear velocity of the crust at the hypocenter, according to the SCEC velocity model. The fault length was determined from the magnitude of the earthquake, assuming an equidimensional fault and a stress drop of $5 \mathrm{MPa}$. In the inversions the corner frequency factor, $\zeta_{S}$, was found to be $0.88 \pm 0.1$. The corner frequencies are shown in Figure 4 and are similar to other estimates for this magnitude range (e.g., Abercrombie, 1995).

Travel times were determined analytically using a linearized version of the $1 \mathrm{D}$ velocity profile beneath each station fit to the SCEC 3D Velocity Model (Magistrale et al., 2000) (Fig. 5). For velocity, $v$, increasing linearly with depth, $z$, as $v(z)=a+b z$, the analytical solution (Lay and Wallace, 1995) for horizontal distance traveled is

$$
x(z)=p \int_{z_{1}}^{z_{2}} \frac{v(z)}{\sqrt{1-(v(z) p)^{2}}} d z .
$$




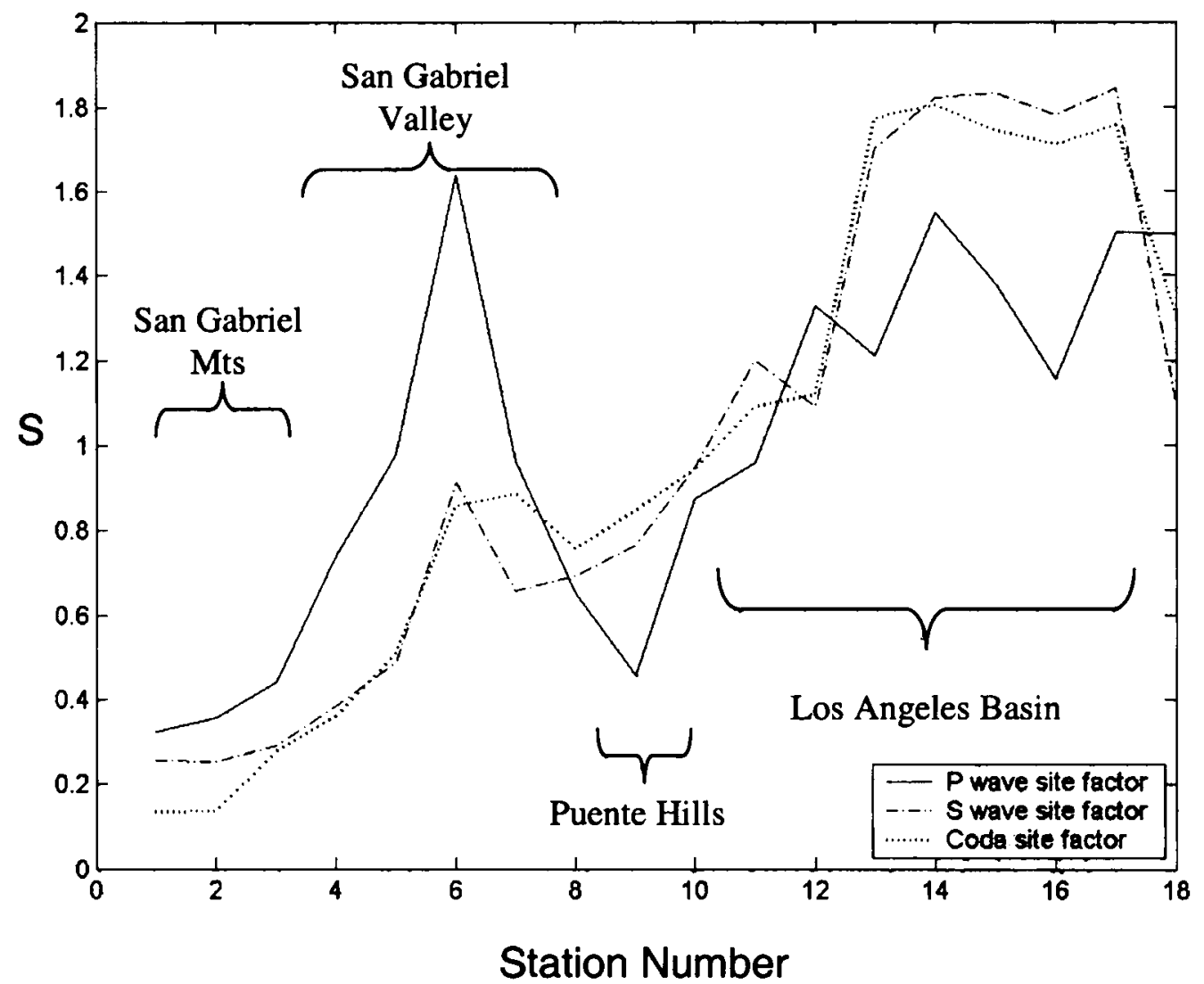

Figure 3. Site Factors. The $P$-wave and $S$-wave site factors are determined from an inversion of equation (1). Coda site factors are determined from coda amplitudes.

This is integrated to give

$$
\begin{aligned}
& x(z)= \\
& \quad-\left.(p b)^{-1} \sqrt{1-(p a)^{2}-2 p^{2} a b z^{\prime}-\left(p b z^{\prime}\right)^{2}}\right|_{z_{1}} ^{z_{2}} .
\end{aligned}
$$

We used two velocity gradients per station: one for the basin and one for the bedrock (Fig. 5). Equation (7) was iterated with varying takeoff angles (by varying ray parameter $p$ ) until the difference between the sum of $x$ in the bedrock and basin and the distance between epicenter and station were minimized. In this simple model, rays from all events are assumed to start in the bedrock gradient and end in the basin gradient as they reach the surface. Even though several were located just inside the basin and a three-gradient model would be more accurate, the model travel times were close to those measured. The travel-time misfit had a standard deviation of 5\%. Thus, the two-gradient model was considered to be sufficiently accurate. The model travel times were used to calculate $T_{i j}$ and $t_{i j l}$ in equation (4). More comprehensive methods were also used to determine travel times, including 2D ray tracing through the SCEC velocity model, but the two-gradient method was most robust and gave comparable results.

Figure $6 \mathrm{a}$ and $\mathrm{b}$ shows the spectral amplitude data for each earthquake plotted against stations 1-18 (numbers increasing from the San Gabriel Mountains to Seal Beach) for the low (Fig. 6a) and high-frequency (Fig. 6b) bands. Arrivals from a cluster of six earthquakes that occurred east of Whittier, approximately $15 \mathrm{~km}$ from station 11, are readily identified by the well-developed spikes in the amplitude pattern affecting stations 9, 10, and 11 on the northern edge of the Los Angeles basin and into the Puente Hills. Maximum values occur at station 11 . These arrivals all come from a narrow range of back azimuths of $110^{\circ}$ to $130^{\circ}$ (Fig. 6a and b) and incident angles. All the events that were amplified had ray paths near the same location on the edge of the Los Angeles basin. Some events from the opposite direction also exhibited high amplitudes at station 11. The fit of the standard model (equation 4) to the data, with site factors $S_{i}$ estimated independently from coda (as described in the preceding section) is shown as the solid line in Figure 6. The misfit at stations $9-11$ is remarkable. The largest of the $S$ wave amplifications occur at station 11. Seismograms for event 21 (Fig. 6a and b) were recorded only on the northsouth component of that seismometer, because the east-west component was faulty during this period. Given this, it is natural to question the validity of the measurement. However, other events were recorded on the same seismometer while the eastern component was faulty that do not have the 


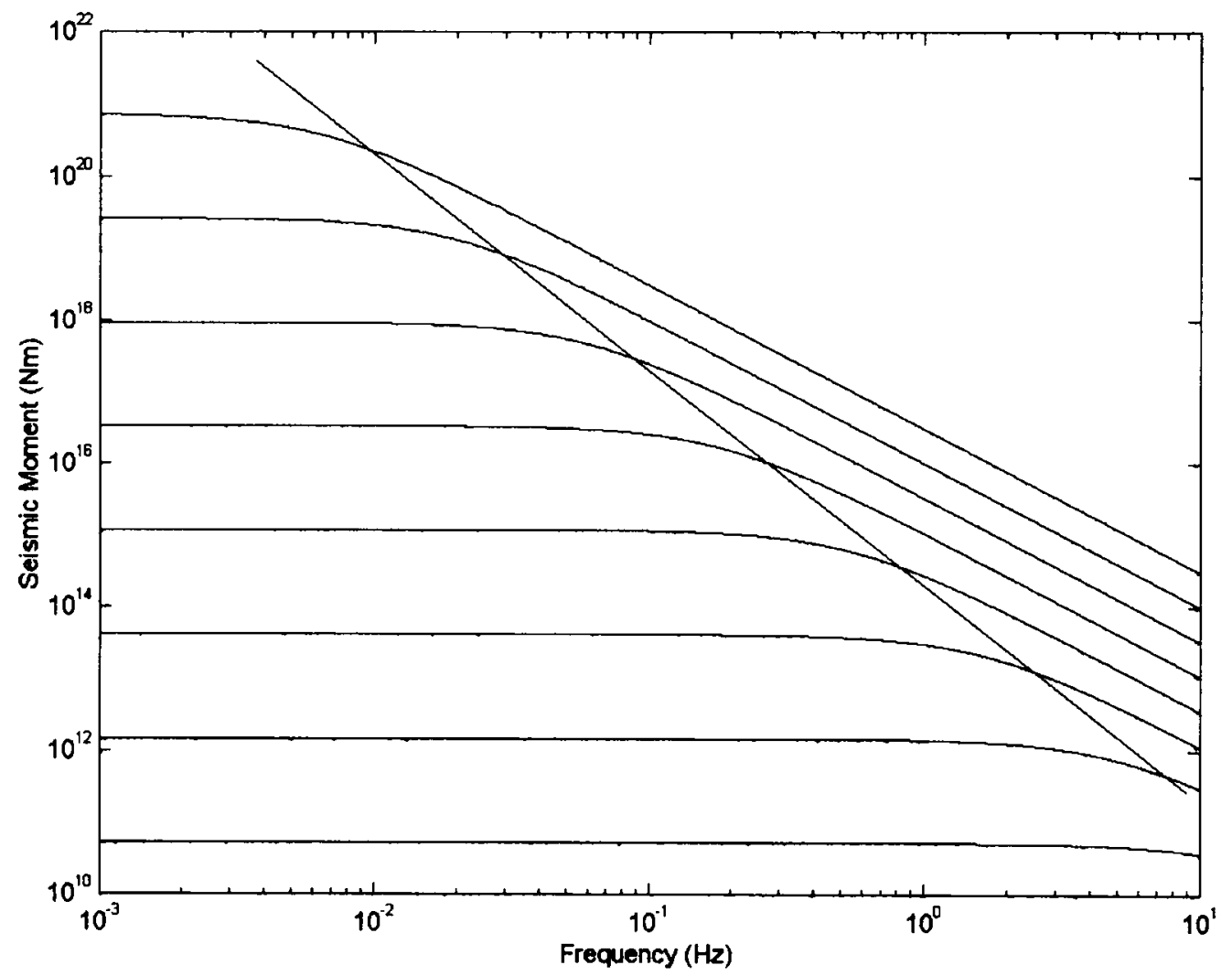

Figure 4. Corner frequencies calculated for magnitudes 1 through 8 using the $\omega^{2}$ model with $\omega_{0}$ determined from our inversion.

amplification. In addition, several other events exhibit a large amplification at that site from similar backazimuths and incidence angles when both components were working. Waveforms from the most focused event (event 21), at station 11 are shown in Figure 7a compared with those from a nonfocused event (Fig. 7b, event 3). The remarkable amplification at station 11 is evident in the raw data (Fig. 7a).

\section{Focal Mechanisms}

A term to account for radiation patterns was applied to those events for which focal mechanisms had been compiled (Hauksson, 2000; Table 1). Equation (4) becomes

$$
\begin{aligned}
& A_{i j}(\omega) \\
& \quad=F_{j}\left(\theta, \phi_{j}\right) S_{i} \frac{\mathrm{E}_{j} \omega}{1+\left(\omega / \omega_{0 j}\right)^{2}} \frac{\exp \left(\sum_{l=1}^{2}-t_{i j l} \omega / 2 Q_{l}(\omega)\right)}{T_{i j}},
\end{aligned}
$$

where $F_{j}\left(\theta, \phi_{f}\right)$ is the amplification due to the radiation pattern of an earthquake for a given station, $\phi_{f}$ is the forward azimuth, and $\theta$ is the takeoff angle (Aki and Richards, 2003). The addition of the radiation term did not improve the fit to the data; in fact, it increased the misfit of the inversion. This could be caused by several factors. Determination of the takeoff angles was based on a simple model of crustal velocities that could be incorrect. Another possibility is that the fault-plane solutions for small events might be inaccurate. Even if either of these possibilities applies, the takeoff angles vary little over the array for a given event, causing little change in the radiation pattern. The more likely explanation is that the radiation pattern is not strong because of scattering in the frequency ranges studied. Given that our data are average spectra of 2- and 4-sec data windows, they probably include energy from both primary phases and scattered phases and may lose the radiation pattern associated with first arrivals. Because our tests indicate that it is unlikely that focal mechanisms could explain the anomalous variation at stations 9-11, radiation patterns were not included in our final analysis.

\section{$P$ waves}

Unlike the $S$ waves, no significant azimuthal concentration in $P$-wave amplification was seen at station 11 (Fig. 8a and b). High amplification was seen at station 6, which sits in the middle of the San Gabriel basin, but this appeared to be explicable as a site effect. It is difficult to tell whether a caustic interpretation might be applicable without an independent estimate of $P$-site factors as we had for $S$ waves 

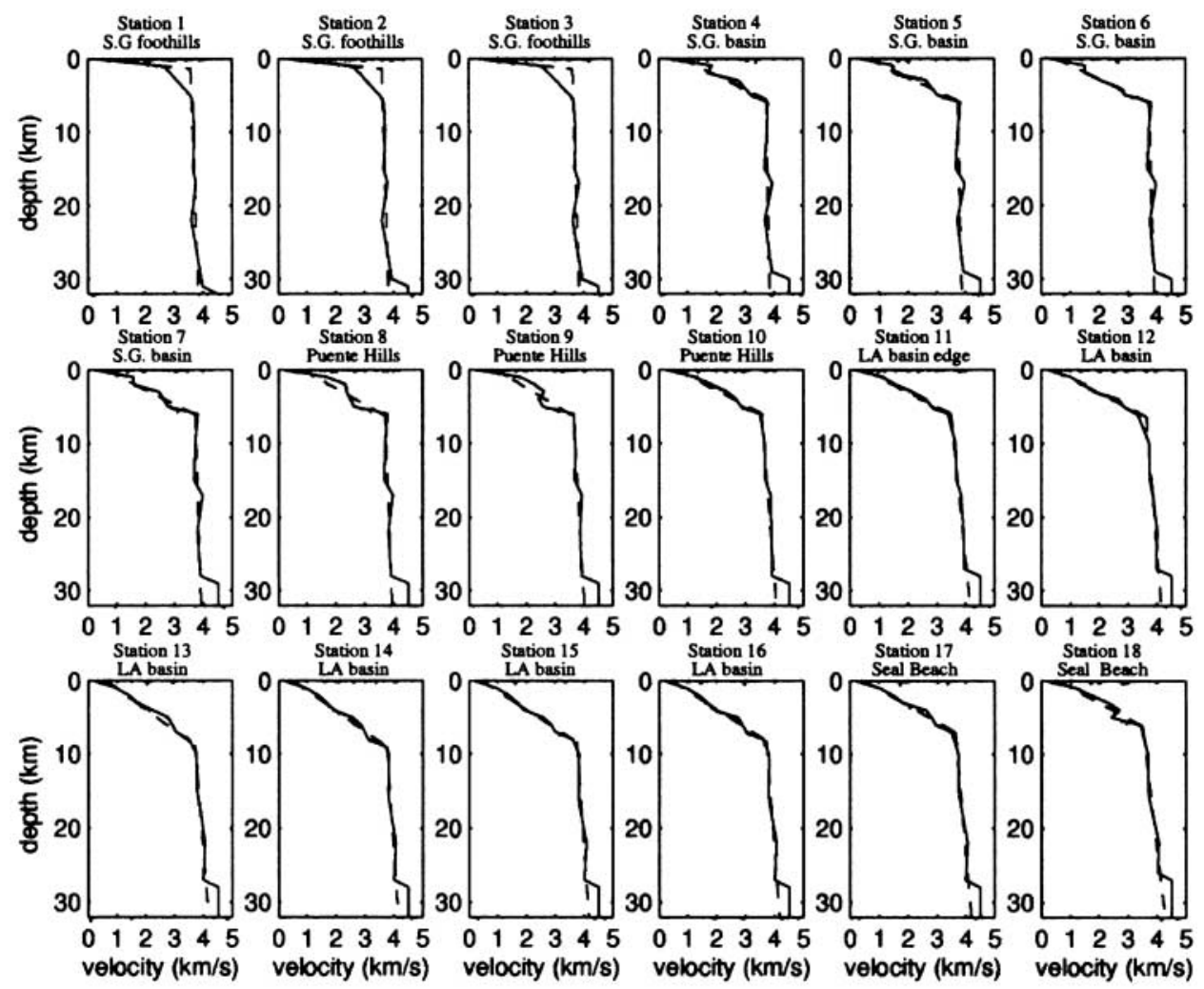

Figure 5. The 1D $S$-wave velocity profile beneath each station taken from the SCEC Velocity Model (Magistrale et al., 2000) (solid line) and the linearized version used in the analytical solution for the ray tracing (dashed line). Stations are plotted left to right, top to bottom from north to south. The depth of the basin is taken to be the point where the slope changes on the dashed line. The $P$-wave velocity profiles are similar but not exactly proportional to $S$-wave velocity.

using $S$ coda. $S$-wave site factors exhibit a maximum at station 6 , so site factor seems a reasonable explanation.

After performing various inversions using equation (4) we found we were unable to resolve $Q_{P}$ in the basin and in the bedrock because the least-squares uncertainties in the respective $Q_{P}$ values are greater than the inverted values. We thus restricted the inversion to solve for low- and highfrequency values averaged over the complete path.

The fit to the $1126 P$-wave data (Fig. 8a and b) is reasonably good. The inverted parameters include 40 event terms, 18 site factors, the corner frequency factor, and the low- and high-frequency $Q_{P}$ values. The variance reduction is $81 \%$. The $Q$ values are low at $96 \pm 11$ and $248 \pm 33$. The frequency factor $\zeta_{P}=1.0 \pm 0.1$ is very similar to the $S$-wave value of $\zeta_{S}=0.88 \pm 0.1$. Although not a central part of our analysis because of the limited range of frequencies used $(1-10 \mathrm{~Hz})$, the fact that both $P$ and $S$ waves give very similar results suggests that when all factors are taken into account the simple "Brune" model, which predicts $\zeta_{P}=\zeta_{S}$, works quite well.

\section{Diffraction Catastrophes}

\section{Application of Catastrophe Theory}

Having eliminated site effects and radiation pattern effects, we tested whether the anomalous arrivals at stations 9-11 fit a model of a basin-edge caustic or catastrophe. Rial (1984) was the first to suggest that caustics in seismology could be described in terms of catastrophe theory. He supposed that a basin exhibits behavior similar to the water droplet models that Berry (1976) used to demonstrate how refracted light creates elevated amplitudes on the droplet surface which can be described as diffraction catastrophes. Catastrophe theory (Thom, 1975) finds that stable caustics fall into just five categories: the fold, cusp, swallowtail, and elliptic and hyperbolic umbilics, where "stable" means that the type of catastrophe remains the same even while the wavefront is perturbed, such as might be expected in a natural (e.g., geological) situation. The most well-known catastrophe, but one of the least stable, is a single focus or point caustic that occurs at the focus of an optical lens (Berry, 


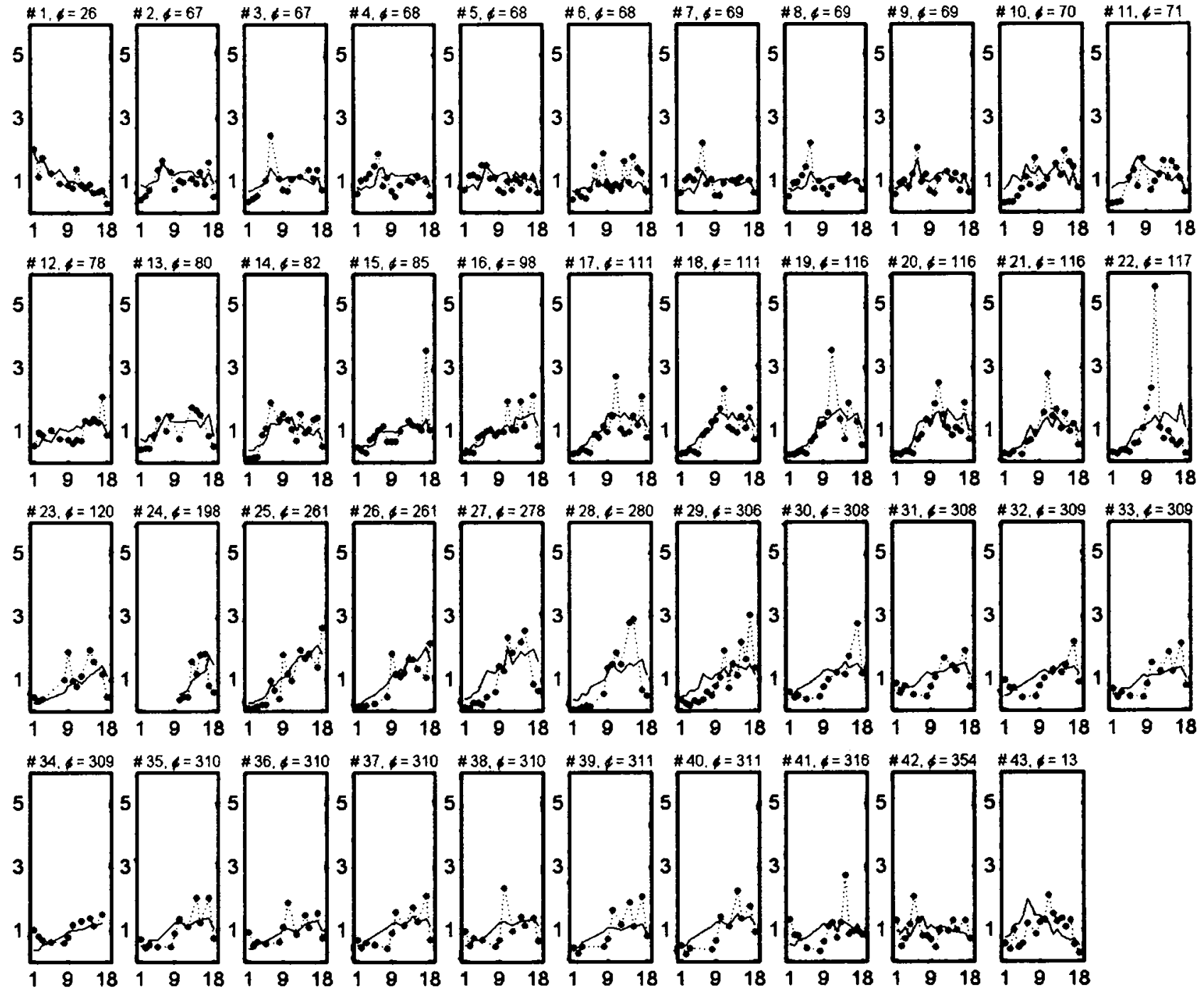

(a)

Station Number

Figure 6. (a) The fits of the standard model (lines) to the data (dotted lines and $*$ ). The data consist of the average spectral amplitudes for the frequency band 1-5 Hz plotted for each of the 43 events. The vertical axes are spectral amplitudes and the horizontal axes are station numbers. $\phi=$ backazimuth. Station 1 is in the foothills of the San Gabriel Mountains, and station 18 is to the south at Seal Beach. Note that the standard model does not fit the group of arrivals at $\phi=111-117^{\circ}$. (continued)

1976). Because of this instability, point caustics are rarely seen in natural environments. Much more stable caustics are folds and cusps (Berry, 1976; Nye, 1985). For example, triplications from the transition zone have been recognized as folds (Nye, 1985). Caustics can be created by taking a 2D slice through the family of rays before they reach a focus, for example, as occurs when the ray paths are intersected by the surface of the Earth. The rays can create complex patterns, but the basic forms on the 2D slice are the line (fold) or the place where lines meet (cusp).

Caustics formed by finite-frequency monochromatic radiation generate Airy and Pearcey diffraction patterns referred to as "diffraction catastrophes" (Berry, 1976). The maximum amplitudes of diffraction catastrophes are frequency dependent (Berry, 1976; Rial, 1984). The amplitude of the fold goes as $\omega^{1 / 6}$, the cusp as $\omega^{1 / 4}$, the swallowtail as $\omega^{3 / 10}$, and the umbilics as $\omega^{1 / 3}$. In contrast, the amplitude of the point focus is proportional to $\omega^{1}$ and the line focus to $\omega^{1 / 2}$ (see Davis et al., 2000 for application to Santa Monica basin-edge data).

\section{Development of the Caustic Model}

In this section we develop an empirical diffraction catastrophe model for the anomalous arrivals. The sharp peaks (Fig. 6) suggested a 1/distance fall-off in amplitude, similar 


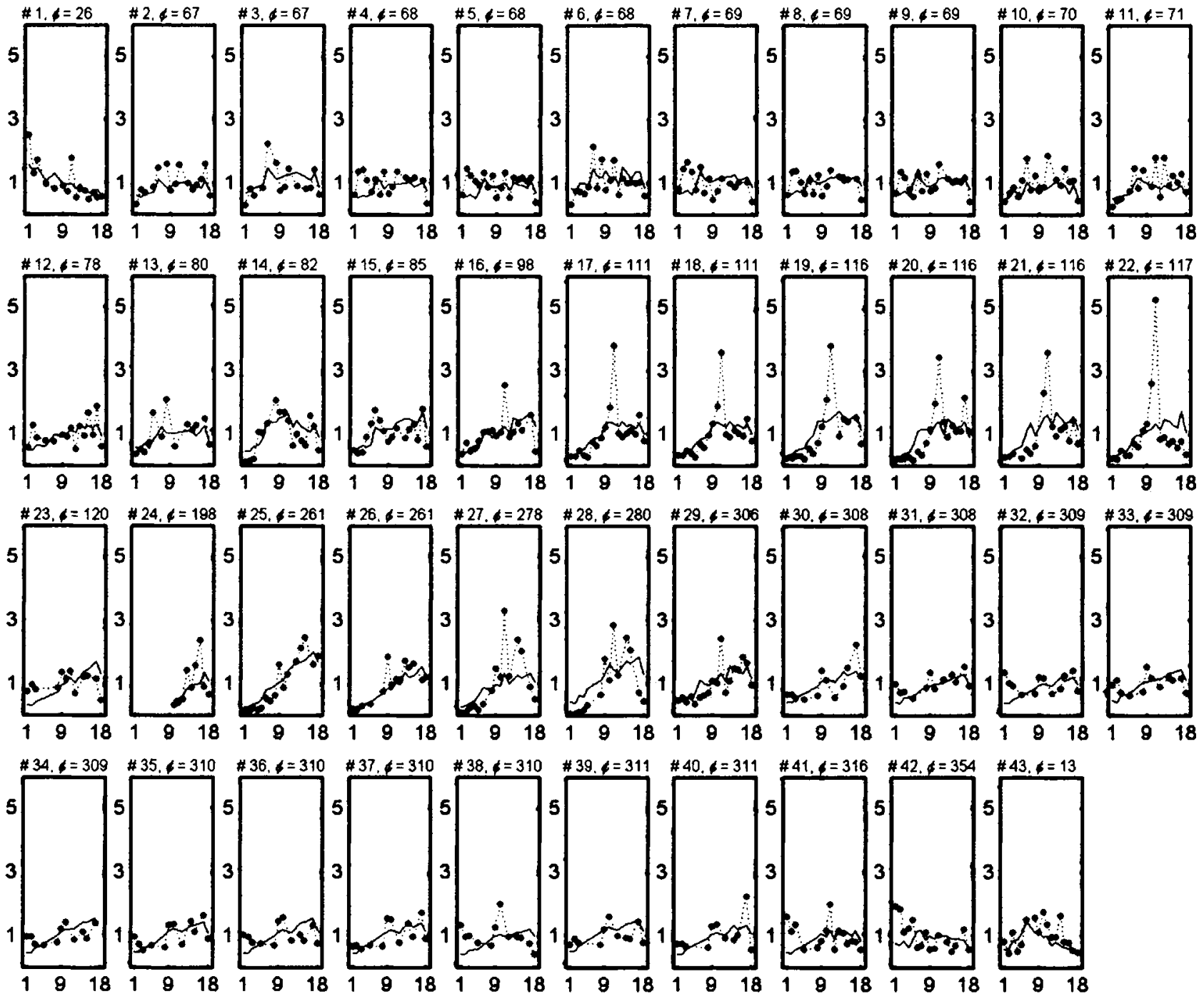

(b)

Station Number

Figure 6. Continued. (b) The fits of the standard model (lines) to the data (dotted lines and *). The data consist of the average spectral amplitudes for the frequency band $5-10 \mathrm{~Hz}$ plotted for each of the 43 events. The vertical axes are spectral amplitudes and the horizontal axes are station numbers. $\phi=$ backazimuth. Station 1 is in the foothills of the San Gabriel Mountains and station 18 is to the south at Seal Beach. Note that the standard model does not fit the group of arrivals at $\phi=111-117^{\circ}$.

to what is seen in Airy and Pearcey diffraction patterns. When multiwavelength radiation is involved, such as in seismology, the nodes of the Airy or Pearcey diffraction patterns will blur. In the infinite-frequency case, Chapman (1976) and Richards (1973) derived a 1/distance fall-off in amplitude for seismic waves forming a caustic by using the Wentzal, Kramers, Jeffreys, and Brillouin (WKJB) approximation to the wave function in a vertical velocity gradient (i.e., triplications). A clue that catastrophe theory might apply is that the amplitude increase with frequency (Fig. 6a compared with b) is evident but fairly small, suggesting a small exponent, $n$, in the $\omega^{n}$ frequency dependence. We have observed that earthquakes with different travel times showed much greater focusing (e.g., event 20), so we included a term to account for travel-time dependence of the maximum amplitude. Taking these considerations into account we used a simple empirical function to model the spectral amplitudes. We envision a high-amplitude zone or bright spot appearing on the surface in the vicinity of station 11 with amplitude determined by how close the travel time, incidence, and azimuth angles are to a maximally focusing path. The amplitude decays from the bright spot across the surface as 1/distance. The brightness has a power-law frequency dependence $\omega^{n}$ but also depends on the earthquake being at the right distance as reflected in the travel time. Equation (4) then becomes 

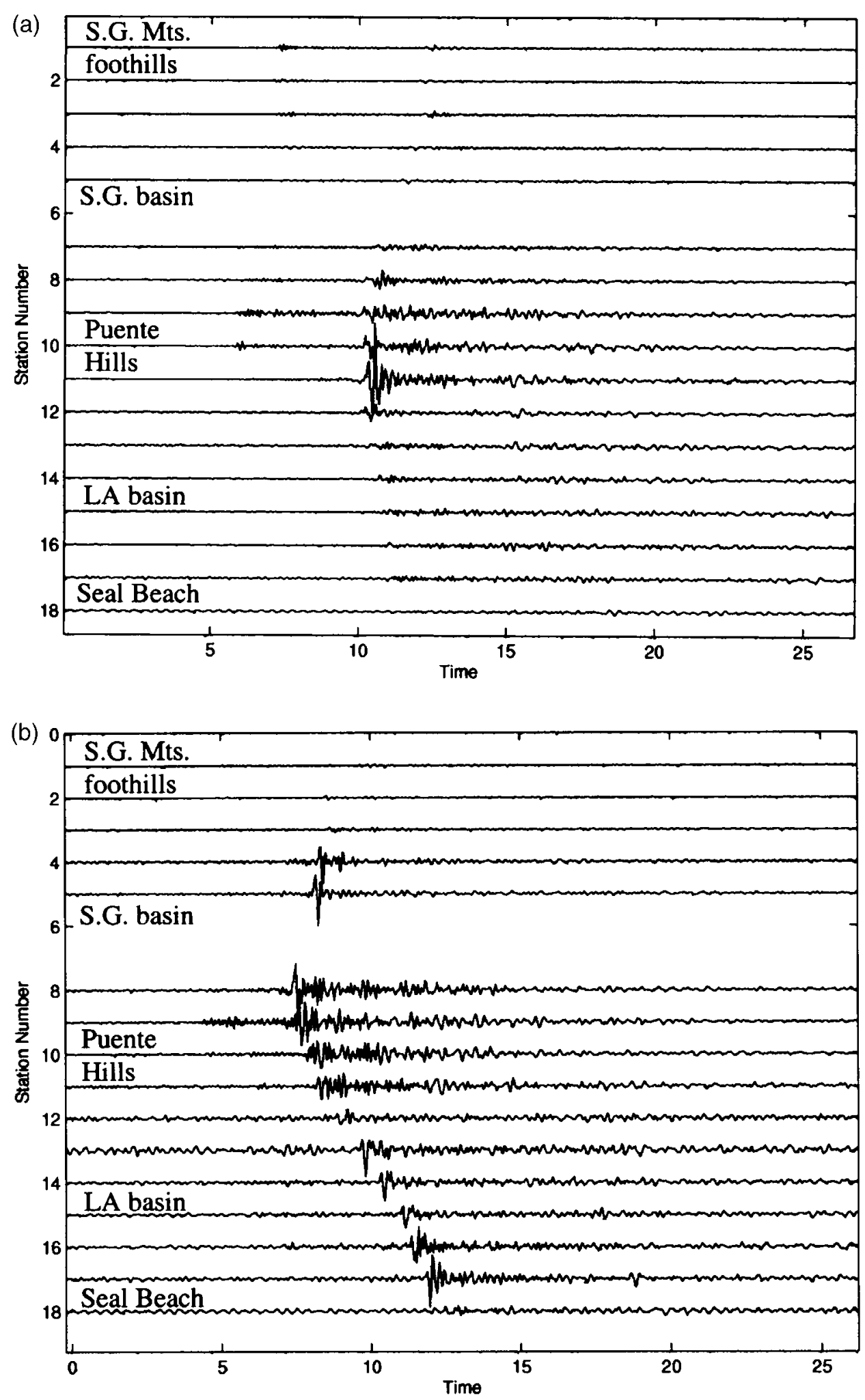

Figure 7. (a) The north-south component of event 22 normalized to the largest amplitude of all stations. Notice the dramatic difference between stations 10-12. (b) This figure shows the north-south component of event 14 normalized to the largest amplitude, in contrast to Figure $7 \mathrm{a}$. Notice that station 11 does not exhibit abnormally large amplification compared with other stations that recorded event 22. 

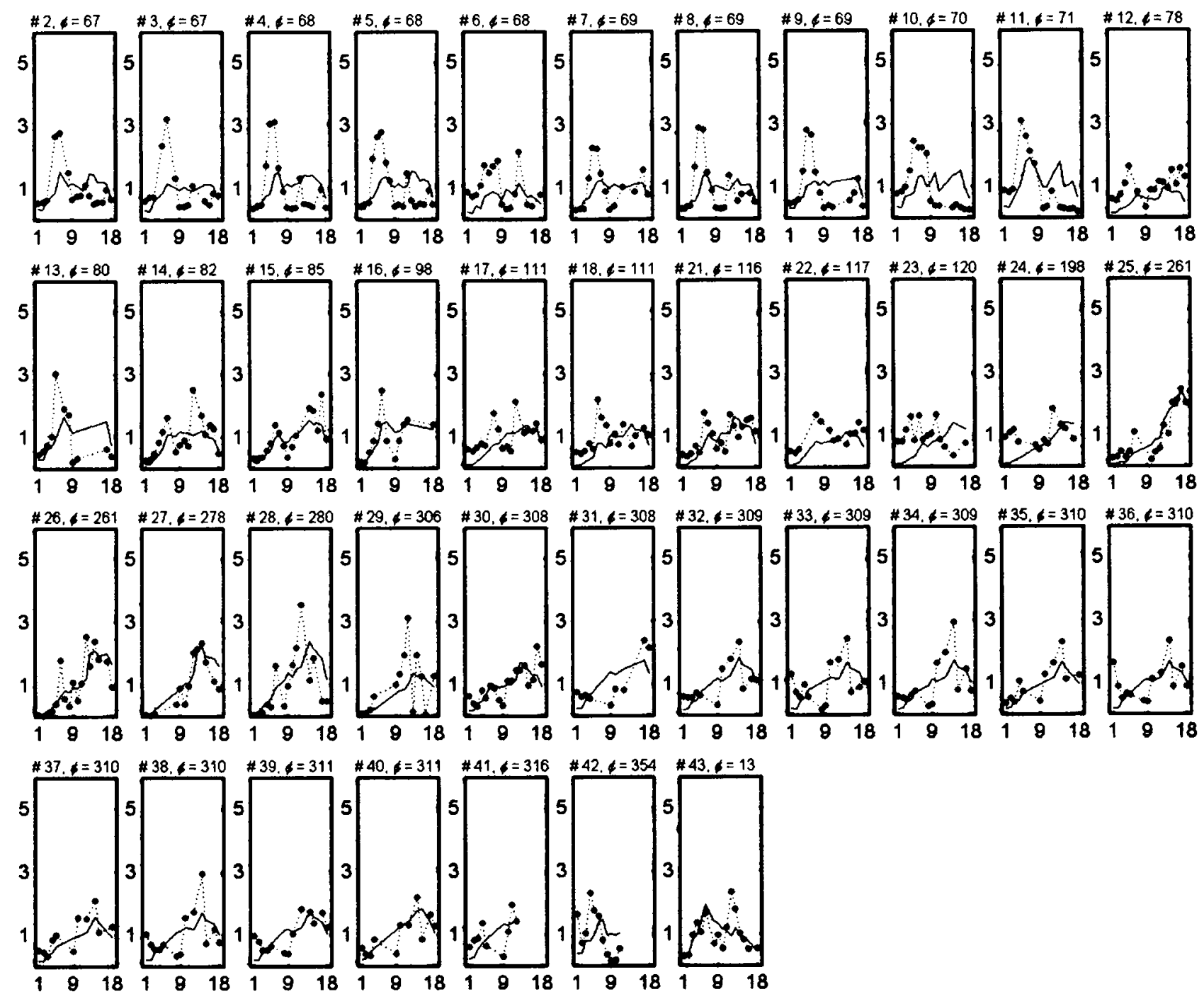

(a)

Station Number

Figure 8. (a) Low-frequency $(1-5 \mathrm{~Hz}) P$-wave spectral amplitudes plotted in the format described in Figure 6.

(continued)

$$
A_{i j}(\omega) \quad C(\theta, \phi) S_{i} \frac{\mathrm{E}_{j} \omega}{1+\left(\omega / \omega_{0 j}\right)^{2}} \frac{\exp \left(\sum_{l=1}^{2}-t_{i j l} \omega / 2 Q_{l}(\omega)\right)}{T_{i j}},
$$

$C(\theta, \phi)$ has been added to take into account caustic effects from a restricted range of incident angles $\theta$ and azimuths $\phi$ and is given by

$$
\begin{aligned}
& C(\theta, \phi)=1 \\
& \quad+\frac{1}{\left(T_{i j}-T_{0}\right)} \frac{C_{0} \omega^{n}}{\sqrt{\left.\left[R_{i j}\left(\theta_{i j}-\theta_{0}\right)\right]^{2}+R_{i j}\left(\phi_{i j}-\phi_{0}\right)\right]^{2}}},
\end{aligned}
$$

where $C_{0}$ is the amplification gain due to the caustic, $R$ is the distance from which the caustic is generated, $\theta$ is the incidence angle, and $\phi$ is the backazimuth. $\theta_{0}$ and $\phi_{0}$ are values where the caustic would be at a maximum (i.e., next to station 11). $T_{0}$ is the travel time for which the amplitude is perfectly focused. We tried a fit with and without this term, but by far the best results occur when it is included. Its inclusion is empirical, however, and takes into account optimal location of the source for focusing. The maximum of equation (9) is infinity, but it is assumed that $\left[T_{0}, \theta_{0}, \phi_{0}\right]$ represents a point offset both temporally and spatially from station 11 and that diffraction would blunt the infinity. Incidence angle $\theta_{i j}$ and distance $R_{i j}$ are measured at the depth where the caustic is generated, that is, near the bedrocksediment boundary. For LABPSE data that is the depth where the $S$-wave velocity becomes $3.3 \mathrm{~km} / \mathrm{sec}(5.6 \mathrm{~km}$ under sta- 


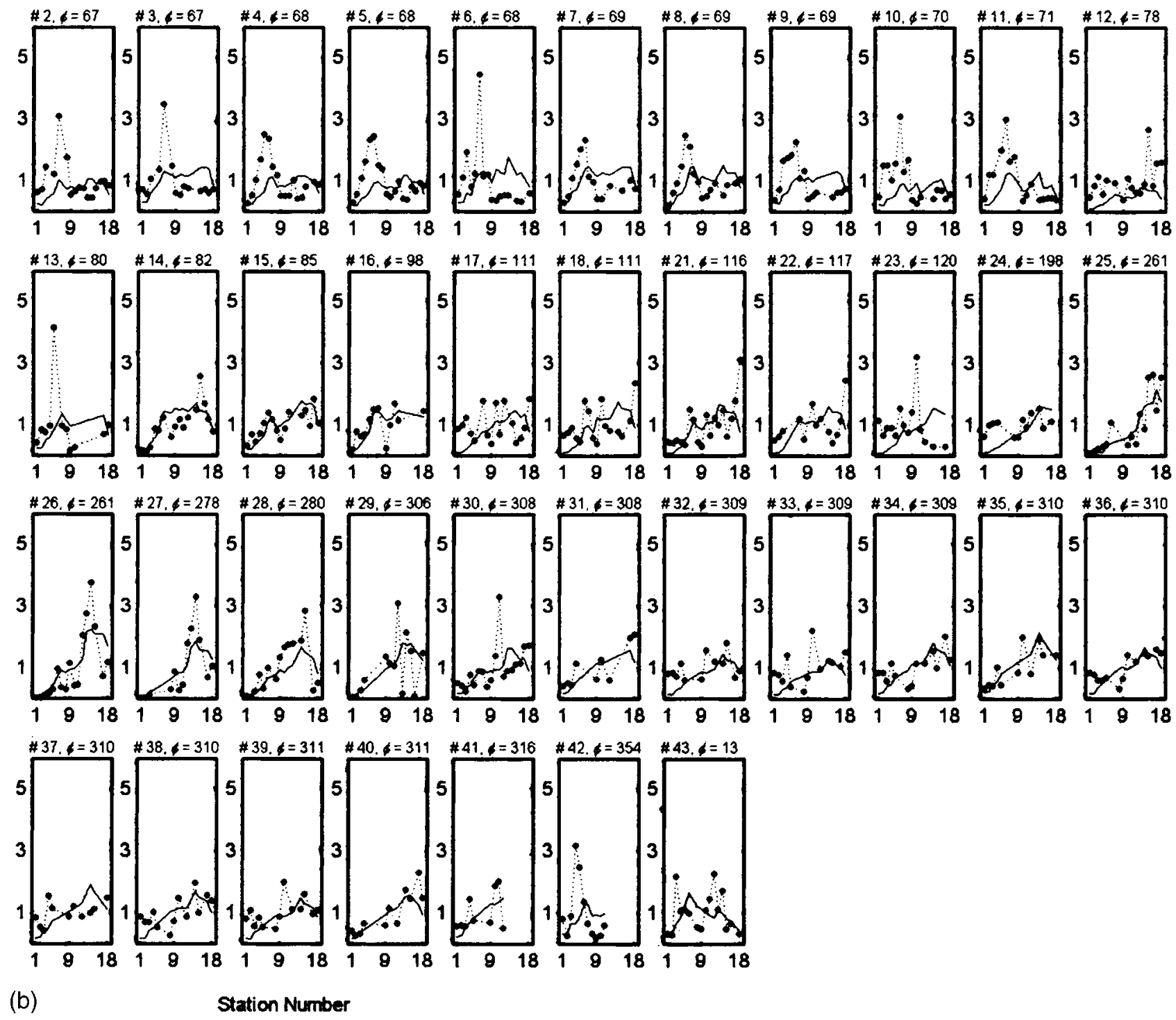

Figure 8. Continued. (b) High-frequency $(5-10 \mathrm{~Hz}) P$-wave spectral amplitudes plotted in the format described in Figure 6.

tion 11). The unknowns in this equation are $T_{0}, C_{0}, \theta_{0}, \phi_{0}$, and $n$. As we shall see this equation fits the data remarkably well, but it must be kept in mind that we are fitting 34 highamplitude data points (six events at stations 9-11 in two frequency bands minus errant components) with five parameters, so the redundancy of data to parameters is marginal.

\section{Test of the Caustic Model Using Spectral Ratios}

Of the stations that exhibit caustic effects, station 11 was the most affected for the six events numbered 17-22 (Fig. 6). We used averaged spectral ratios for these seismograms to compute the caustic exponent (equation 10). If we consider two hypothetical nearby stations that record the same event, and one is affected by a caustic but the other is not, their spectral ratio (equation 9/equation 8) will cancel out frequency effects of $Q$ and the source. The ratio should be proportional to the caustic term (equation 10) and the spectral ratio can be used to determine the frequency exponent, $n$. Because of noise, spectral ratios can produce unrealistically high values where the denominator approaches zero. To suppress this, we used the average spectra from stations 1-6 in the denominator, and spectra from the caustic events at station 11 in the numerator. As a comparison we repeated the procedure for the remaining 37 noncaustic events. Finally to reduce noise we averaged the caustic and noncaustic ratios at station 11 . The results are shown in Figure 9.

Let $S_{i j}(\omega)$ be the $S$-wave spectrum (at 51 frequencies) at station $i$ for event $j$. The spectral ratio $C_{j}(\omega)$ for the caustic events measured at station 11 , relative to the average spectra of stations $1-6$, is given by 


$$
\begin{aligned}
C_{j}(\omega) & =S_{k j}(\omega) / \sum_{i=1}^{6} S_{i j}(\omega) j=\{\text { events }\}, k=11 \\
\bar{C}(\omega) & =\sum_{i=1}^{6} C_{j}(\omega) / 6 .
\end{aligned}
$$

Figure 8 shows $\bar{C}(\omega)$ for the caustic events (upper curve, $j=17-22)$ and the noncaustic events measured at station 11 (lower curve, $j=1-16,23-43$ ). We see that the average spectral ratio for the noncaustic events is flat, which supports our choice of stations $1-6$ as a reference. For the caustic events however, $\bar{C}(\omega)$ increases with frequency and a fit of equation (10) gives an exponent of $0.25 \pm 0.06$. The amplification is several times that of the noncaustic events. This is what is expected if the source of the extra amplification is a diffraction catastrophe cusp. The errors are large enough that a fold, swallowtail, or umbilic cannot be ruled out, however. In the next section on data inversion, we use $n=0.25$.

\section{$S$ Wave Inversion Results Including a Cusp}

Having determined that the anomalous variation could not be explained by radiation pattern or anomalous site effects, we inverted the $1272 S$-wave spectral amplitude (636 low-frequency and 636 high-frequency) data using equation (9) to obtain the 43 event terms $E_{i}, 18$ site terms $S_{i}, 4$ attenuation terms (low/high-frequency bedrock/basement $Q_{s}$ ), the 4 caustic terms of equation (10) and the corner frequency factor $\zeta_{s}$. In some inversions, greater weight was given to the peak caustic data (by a factor of 4 ) in the inversion. The site terms were constrained to be those found in the coda analysis (see Coda $Q$ and Site Factors section) by adding the coda values as a priori data in a nonlinear Bayesian inversion (Jackson and Matsuura, 1985). Without this constraint the inverted site terms exhibited similar spikes to the caustics, but less strong. This occurred because arrivals from other azimuths do not show caustic effects. They represent a compromise in fitting the caustic and noncaustic data, but do a poor job for both. The inversion results and standard deviations are listed in Tables 1,2,3. The variance reduction is $81 \%$. The fit of the model is shown in Figure 10a and b.

For the caustic model with frequency dependence, the exponent was set to $n=0.25$ based on the spectral ratio analysis (see preceding section), we obtain $\phi_{0}=114^{\circ}$ and $\theta_{0}=78^{\circ}$. For comparison, the values for the highest observed peak seen in the data (station 11, event 22) are $\phi_{11,22}=117^{\circ}$ and $\theta_{11,22}=69^{\circ}$.

The $Q$ values given in Table 2 show greater attenuation in the basin versus the bedrock, and higher attenuation of the low-frequency band than the high-frequency band. Table 2 also lists the attenuation values with the coda $Q$ values and those obtained by Frankel (1991), showing that we obtained similar results where the coda $Q$ was much higher than the direct-wave $Q$.

Finally, to test whether the inversion results were sensitive to the frequency bands chosen, we repeated the pro- cedure for four bands $(1-3,3-6,6-9$, and 9-12 Hz). We obtained similar inversion results but the fits were very noisy especially at the outer bands where the signal-to-noise ratio is lowest.

\section{Discussion of Results}

Our interpretation that the anomalous amplitudes seen along the edge of the Los Angeles Basin were due to catastrophe effects relied on separating out propagation and site effects. In particular, to find the frequency exponent for the catastrophe model required taking attenuation into account. The attenuation results of this study are similar to previous findings (Frankel, 1991; Hough et al., 1988; Mayeda et al., 1992), which adds confidence that they can be effectively removed. Attenuation for frequencies greater than $1 \mathrm{~Hz}$ is generally found to be frequency dependent with $Q$ values increasing with frequency (Padhy, 2005), but the relative importance of intrinsic attenuation versus scattering attenuation is not understood (Mayeda et al., 1992; Frankel, 1991; Aki, 1980). Mayeda et al. (1992) examined the change of the coda spectrum due to distance from the epicenter and found that scattering attenuation dominated at frequencies below $6 \mathrm{~Hz}$, whereas intrinsic attenuation dominated above $6 \mathrm{~Hz}$. Aki (1980) used results from single scattering models (Aki and Chouet, 1975) to suggest that coda $Q\left(Q_{C}\right)$ was equivalent to the $Q$ of the direct shear waves $\left(Q_{s}\right)$. Frankel used results from a multiscattering model (Frankel and Clayton, 1986; Frankel and Wennenberg, 1987) to suggest that if scattering energy was conserved, $Q_{C}$ should be greater than $Q_{S}$ because the multiscattered, high-frequency radiation would then appear later in the coda rather than become lost (for example, converted to heat). Frankel (1991) compared $Q_{C}$ and $Q_{S}$ from arrays in southern California, New York, and South Africa to support this view, finding that highfrequency $(15-30 \mathrm{~Hz}) Q_{C}$ was twice as large as $Q_{S}$.

We find, as did Frankel (1991), that $Q_{C}$ is twice as large as $Q_{S}$. Average values of $Q_{S}$ in basin and bedrock, $Q_{P}$ and $Q_{C}$ from the inversion, are given in Table 2. $Q_{S}$ was found to be greater by about a factor of 3 in bedrock than in the basin. High-frequency $Q$ is greater than low-frequency $Q$ for both $P$ and $S$ waves. We can make no direct comparison of $Q_{P}$ and $Q_{S}$ because $Q_{P}$ was not separable into basin and bedrock. We compare our attenuation values with those given by Frankel (1991) for southern California (Table 2). We cannot directly compare our results with Mayeda et al.'s (1992) frequency dependence of intrinsic and scattering attenuation results because we analyze different parts of the waveform. However, with our less detailed study of attenuation, we can confirm the conclusions of Frankel (1991). Like Frankel (1991) we find that the coda decays at a slower rate than the direct wave front (i.e., $Q_{C}>Q_{S}$; see Table 2). In addition, high-frequency energy, which is trapped more effectively, decays at a slower rate than low-frequency energy (i.e., $Q_{\text {high freq }}>Q_{\text {low freq; }}$; see Table 2). Our results differ from Frankel's (1991) in that $Q_{S}$ values were relatively simi- 




Figure 9. (upper curve) Averaged spectral ratios for the caustic events (17-22) measured at station 11 divided by average spectra over stations 1-6. The smooth curve is a fit of the caustic equation (10) to the data. The lower curve is the averaged spectral ratios for the noncaustic events. It has both lower amplitude and a flat variation that is consistent with the assumption that stations 1-6 are representative of noncaustic behavior.

Table 2

$Q$ Values from Our Study Compared with Frankel's (1991) $Q$

\begin{tabular}{|c|c|c|c|c|c|c|c|}
\hline \multirow{2}{*}{$\begin{array}{l}\text { Frequency } \\
\quad(\mathrm{Hz})\end{array}$} & \multicolumn{4}{|c|}{ This Study } & \multicolumn{3}{|c|}{ Frankel } \\
\hline & & $Q_{S}$ & $Q_{P}$ & Coda $Q_{C}$ & Frequency $(\mathrm{Hz})$ & Direct-S $Q_{S}$ & Coda $Q_{C}$ \\
\hline $1-5$ & $\begin{array}{l}\text { Bedrock } \\
\text { Basin }\end{array}$ & $\begin{array}{c}137 \pm 13 \\
61 \pm 7\end{array}$ & $96 \pm 10$ & 264 & 3 & 110 & 130 \\
\hline $5-10$ & $\begin{array}{l}\text { Bedrock } \\
\text { Basin }\end{array}$ & $\begin{array}{l}373 \pm 42 \\
174 \pm 26\end{array}$ & $248 \pm 33$ & 446 & 151 & 310 & 540 \\
\hline
\end{tabular}

The $Q_{s}$ values are taken from the full inversion that includes equations (1) and (9). The variance reduction for the $P$-wave inversion was $75 \%$, and for the $S$-wave inversion it was $81 \%$.

Table 3

Inverted Parameters for the Corner Frequencies and the Caustic Found on the $S$-Wave Terms

$\begin{array}{lr}\text { Corner frequency } & \\ \zeta_{P} & 1.0 \pm 0.1 \\ \zeta_{S} & 0.88 \pm 0.1 \\ \text { Diffraction caustic } & \\ \text { C } & 6202 \pm 145 \\ \theta_{0} \text { (degrees) } & 78.1 \pm 1.9 \\ \phi_{0} \text { (degrees) } & 113.7 \pm 01.7 \\ n & 0.25 \pm 0.06\end{array}$

lar but our values of $Q_{C}$ are greater, supporting the view that more scattering occurs in the Los Angeles basin. This probably occurs because the Los Angeles basin area has more unconsolidated material than the region to the east where his array was centered and therefore experiences more scattering.
Our observation that a diffraction catastrophe occurred at the edge of the Los Angeles basin and into the Puente Hills relies on ruling out site effects. We were alerted to this possibility when we noticed that arrivals at stations 9-11 were only amplified from critical azimuths, that is, those along the basin edge. We estimated site affects from coda decay amplitudes which showed an overall correspondence with basin depth, but site effects did not peak at stations where the largest amplitudes were observed. At the edge of the Los Angeles basin there is a horizontal positive velocity gradient out of the basin to the north, in addition to the positive velocity gradient with depth. We infer that multipathing caused by diving rays in addition to rays redirected horizontally gave rise to the caustic.

By inspection of Figure $6 a$ and $b$ we see that the anomalous amplitudes increase by about $20 \%$ when frequency doubles, accounting for the frequency exponent $n=0.25$ \pm 0.06 in equation (10). This value corresponds to a cusp 

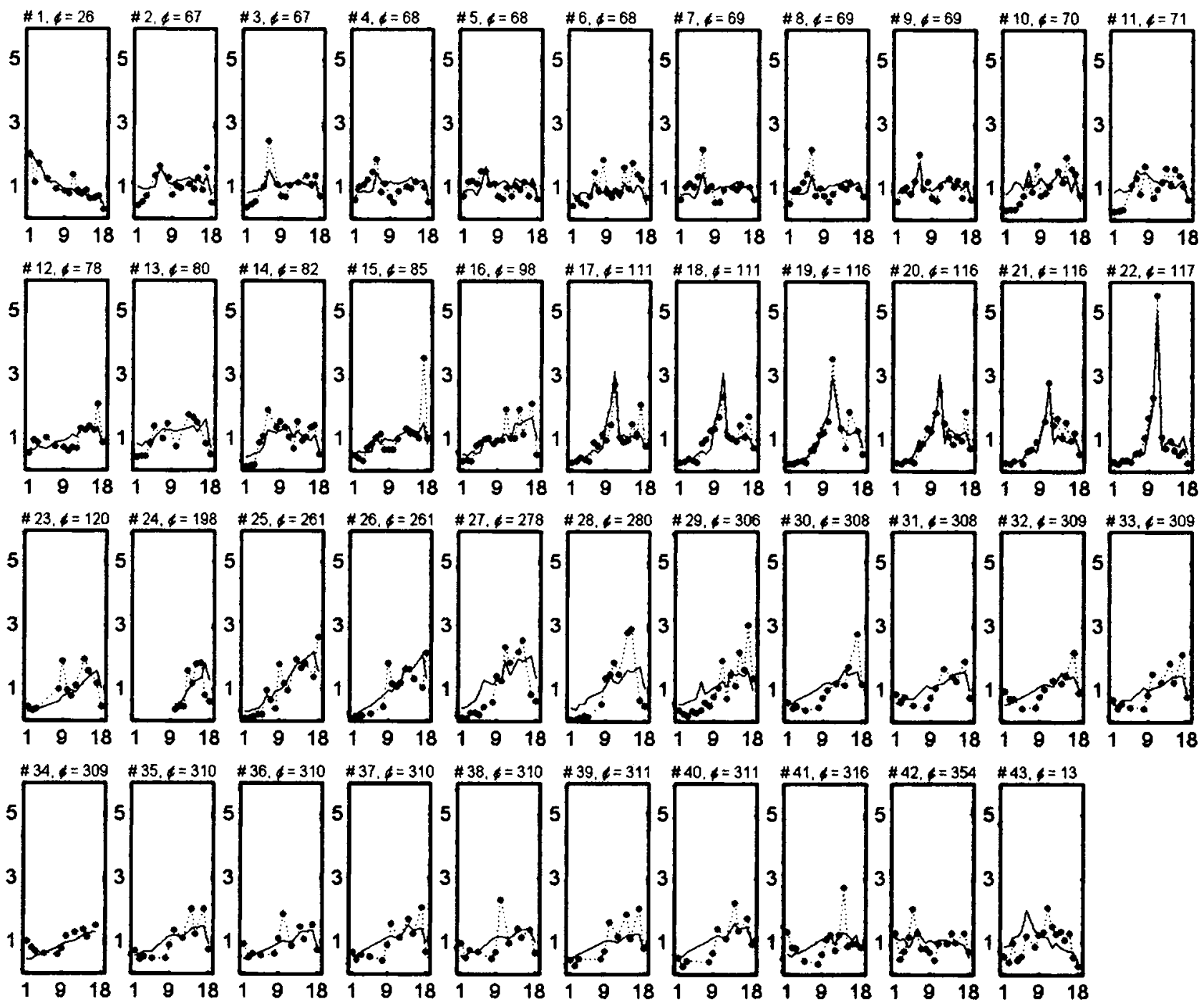

(a)

Station Number

Figure 10. (a) Low-frequency $(1-5 \mathrm{~Hz}) S$-wave spectral amplitudes plotted in the format described in Figure 6. Backazimuths between $120^{\circ}$ and $124^{\circ}$ (events 17-22) exhibit a spike at station 11. A caustic (equation 9) is included in the model for events $17-22$.

(continued)

catastrophe $(n=0.25)$ but the range of 0.19 to 0.31 admits other possibilities. The lowest theoretical exponent $(n=$ $0.1667)$ is the fold catastrophe, which has amplitude variation described by the Airy function given by

$$
A(r, k)=k^{1 / 6} \frac{2 \pi}{3^{1 / 3}} A i\left(\frac{k^{2 / 3} r}{3^{1 / 3}}\right)
$$

where $r$ is distance and $k$ is the wavenumber. We were able to fit the data with absolute values of the Airy function (equation 12) nearly as well as the simple model of equation (10). The interference of two folds gives rise to a cusp. The exponent in the inversion $(n=0.25)$ suggests that the catastrophe is closer to a cusp $(n=0.25)$ than a fold $(n=$
$0.167)$ but, given the uncertainties and covariance of the estimate with other parameters in addition to the difficulties with station 11, it is not possible to identify which particular catastrophe has occurred. A fold is more likely to occur along a basin edge, but a more comprehensive experiment would be needed to eliminate other possibilities.

Coda site factors, in general, gave good estimates of $S$ wave site factors and averaged out azimuthal effects (Fig. 3). Using this method to determine site factors, however, assumes, that the scattering model is common to all earthquake-site pairs and that the only difference in the coda is the local amplification at the site. The very low coda-derived site factors at nonbasin stations 1-3 in the San Gabriel foothills, compared with those of the joint inversion, suggest that the scattering is less and the coda-derived site terms are 


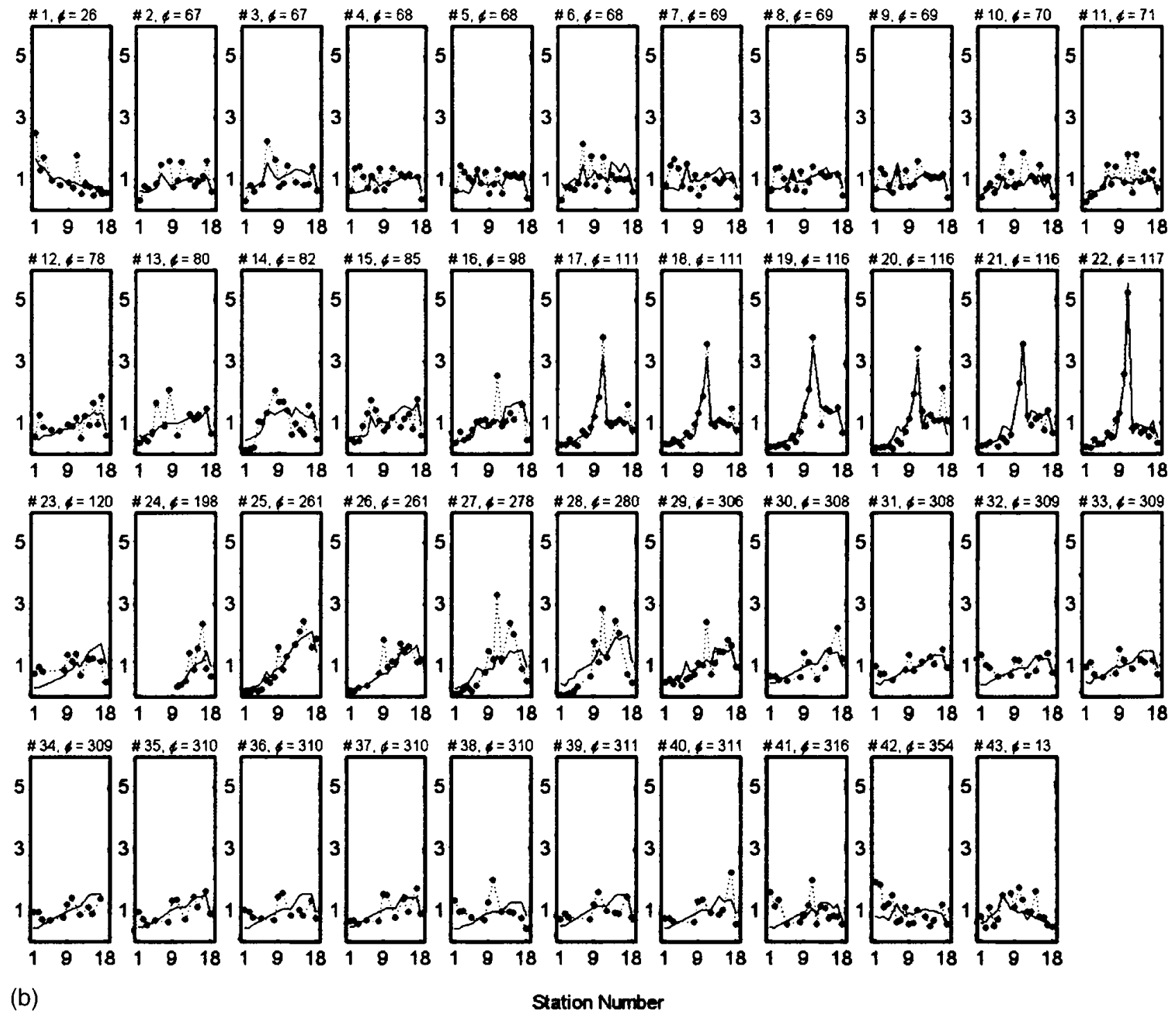

Figure 10. Continued. (b) High-frequency $(5-10 \mathrm{~Hz}) S$-wave spectral amplitudes plotted in the format described in Figure 6. Backazimuths between $120^{\circ}$ and $124^{\circ}$ (events 17-22) exhibit a spike at station 11. A caustic (equation 9) is included in the model for events $17-22$.

biased low. Using a combination of both direct-wave site factors $S_{i}$ and coda values in the constrained inversion eliminates contamination from both a nonuniform scattering model and caustic effects.

We do not understand why the strong basin-edge amplification was only seen in the $S$ waves and not the $P$ waves, but we suppose that the spatial variation in the $P / S$ velocity ratio is enough to eliminate the caustic in the $P$ waves. This contrasts with the observation in Santa Monica data (Gao et al., 1996) that focusing occurred for both $P$ and $S$ waves. We also note that the Santa Monica data were interpreted in terms of point foci of lens theory (Davis et al., 2000). Our work suggests that an interpretation in terms of diffraction catastrophes is probably more applicable (J. F. Nye, personal comm., 2001). Both exhibit a $1 /$ distance fall-off, the main difference being that the exponent in the frequency dependence is $n=1 / 6$ to $1 / 3$ for a diffraction catastrophe and $n=1$ for a lens. This and the greater stability of catastrophes make them more likely candidates for explaining bright spots in a natural system.

Other mechanisms that might have given rise to observed high amplifications include trapped waves in the Whittier fault system that runs along the Puente Hills or highly azimuth-dependent resonant site effects. These effects appear to be less likely but are not easily ruled out with the available data set. Complete understanding of this 
phenomenon will require installation of 2D seismic arrays along basin edges. Because seismic waves become uncorrelated at distances greater than a wavelength, the station spacing of an ideal array would be on the order of 100 meters rather than the several kilometer spacing as used here.

\section{Conclusion}

We analyzed seismograms from local earthquakes recorded by a temporary array of seismometers that ran across the Los Angeles basin. The data were converted to average $P$ - and $S$-wave spectral amplitudes in the $1-5 \mathrm{~Hz}$ and 5-10 $\mathrm{Hz}$ bands and were inverted for site effects and attenuation, assuming an $\omega^{2}$ source model and 1/distance geometric spreading. After taking these factors into account we found evidence for a caustic on the northern edge of the Los Angeles basin from a group of earthquakes incident along the basin edge.

We determined $Q_{S}$ in different spatial regions (bedrock and basin) by weighting the attenuation factor by the time the ray was in bedrock or basin as determined by ray tracing through the SCEC velocity model. We found differences in $Q$ during different temporal sections of the waveform $(P, S$, direct waves, and coda) and attributed them to the effects of scattering. We found that the standard model worked well for $97 \%$ of the data except for specific path effects due to basin-edge structures from a narrow range of backazimuths. Stations on the northern end of the Los Angeles basin (stations 9-11) exhibit a basin-edge effect for $S$ waves that can be accounted for by the addition of a caustic modeled as a diffraction catastrophe. Our interpretation that the anomalous basin arrivals form a caustic is based on the following observations: (1) site effects, radiation pattern, and attenuation were unable to explain the anomalous arrivals; (2) the spatial decay in amplitude corresponds to an inverse distance variation; (3) the frequency dependence fits that expected from a diffraction catastrophe; and (4) the basin edge has both vertical and horizontal gradients that can lead to multipathing to generate a caustic. Diffraction catastrophes may be quite common in regions of lateral heterogeneity and may account for anomalous damage such as that from the 1967 Caracas and 1994 Northridge earthquakes. Seismic array experiments using 2D networks with stations at 100-m spacing are needed to fully resolve the phenomenon. Earthquake engineers need to be aware of the potential consequences of diffraction catastrophes on the amplitudes of ground shaking because standard models may underestimate localized amplification by a factor of up to 5 .

\section{Acknowledgments}

Thanks to Aaron Martin for LABPSE installation and maintenance. We thank J. F. Nye for suggesting that catastrophe theory might be applicable. This work was supported by grants from the UCLA NSF Science and Technology Center for Embedded Networked Sensing (CENS; NSF
STC award CCR-0120778) and by the Southern California Earthquake Center (SCEC). SCEC is funded by NSF Cooperative Agreement EAR-0106924 and USGS Cooperative Agreement 02HQAG0008. The SCEC contribution number for this article is 917 . Support was also provided by U.S. Geological Survey grant 1434-HQ-97-R-3000. Shirley Baker is thanked for help with field work.

\section{References}

Abercrombie, R. E. (1995). Earthquake source scaling relationships from -1 to $5 M_{\mathrm{L}}$ using seismograms recorded at $2.5-\mathrm{km}$ depth, J. Geophys. Res. 100, 24,015-24,036.

Aki, K. (1967). Scaling law of seismic spectrum, J. Geophys. Res. 72, $1217-1231$.

Aki, K. (1980). Scattering and attenuation of shear waves in the lithosphere. J. Geophys. Res., 85, 6496-6504.

Aki, K., and B. Chouet (1975). Origin of coda waves: source, attenuation, and scattering effects, J. Geophys. Res. 80, 3322-3342.

Aki, K., and P. G. Richards (1980). Quantitative Seismology, W. H. Freeman, San Francisco.

Berry, M. V. (1976). Waves and Thom's theorem, Adv. Phys. 25, 1-26.

Brune, J. N. (1970). Tectonic stress and the spectra of seismic shear waves from earthquakes, J. Geophys. Res. 75, 4997-5009.

Chapman, C. H. (1976). A first motion alternative to geometrical ray theory, Geophys. Res. Lett. 3, 153-156.

Davis, P. M., J. L. Rubinstein, K. H. Liu, S. S. Gao, and L. Knopoff (2000). Northridge Earthquake damage caused by geologic focusing of seismic waves, Science 289, 1746-1750.

Frankel, A. (1991). Mechanisms of seismic attenuation in the crust: scattering and anelasticity in New York State, South Africa, and Southern California, J. Geophys. Res. 96, 6269-6289.

Frankel, A., and R. W. Clayton (1986). Finite difference simulations of seismic scattering: implications for the propagation of short period seismic waves in the crust and models of crustal heterogeneity, $J$. Geophys. Res. 91, 6465-6489.

Frankel, A., and L. Wennenberg (1987). Energy flux model of seismic coda: separation of scattering and intrinsic attenuation, Bull. Seism. Soc. Am. 77, 1223-1251.

Gao, S., H. Liu, P. M. Davis, and L. Knopoff (1996). Localized amplification of seismic waves and correlation with damage due to the Northridge Earthquake: evidence for focusing in Santa Monica, Bull. Seism. Soc. Am. 86, S209-S230.

Hauksson, E. (2000). Crustal structure and seismicity distribution adjacent to the Pacific and North America plate boundary in southern California, J. Geophys. Res. 105, 13,875-13,903.

Hough, S. E., J. G. Anderson, J. Brune, F. Vernon III, J. Berger, J. Fletcher, L. Haar, T. Hanks, and L. Baker (1988). Attenuation near Anza, California, Bull. Seism. Soc. Am. 78, 672-691.

Jackson, D. D., and M. Matsu'ura (1985). A Bayesian approach to nonlinear inversion, J. Geophys. Res. 90, 581-591.

Kohler, M. D., B. C. Kerr, and P. M. Davis (2000). The 1997 Los Angeles basin passive seismic experiment-a dense, urban seismic array to investigate basin lithospheric structures, U.S. Geol. Surv. Open-File Rept. 00-148, 109 pp.

Lay, T., and T. C. Wallace (1995). Modern Global Seismology, Academic Press, San Diego.

Magistrale, H., S. Day, R. W. Clayton, and R. Graves (2000). The SCEC Southern California reference three-dimensional seismic velocity model version 2, Bull. Seism. Soc. Am. 90, S65-S76.

Mayeda, K., S. Koyanagi, M. Hoshiba, K. Aki, and Y. Zeng (1992). A comparative study of scattering, intrinsic, and coda $\mathrm{Q}^{-1}$ for Hawaii, Long Valley, and central California between 1.5 and $15.0 \mathrm{~Hz}, J$. Geophys. Res. 97, 6643-6659.

Nye, J. F. (1985). Caustics in seismology, Geophys. J. R. Astr. Soc. 83, $477-485$. 
Padhy, S. (2005). A scattering model for seismic attenuation and its global applications, Physi. Earth Planet Interiors 148, no. 1, 1-12.

Rial, J. A. (1984). Caustics and focusing produced by sedimentary basins: applications of catastrophe theory to earthquake seismology, Geophys. J. R. Astr. Soc. 79, 923-938.

Richards, P. G. (1973). Calculation of body waves, for caustics and tunneling in core phases, Geophys. J. R. Astr. Soc. 35, 243-264.

Stacey, F. D. (1992). Physics of the Earth, Brookfield Press, Queensland, Australia.

Steck, L., A. Prothero, and J. Scheimer (1989). Site dependent coda Q at Mono Craters, California, Bull. Seism. Soc. Am. 79, 1559-1574.
Thom, R. (1975). Structural Stability and Morphogenesis: An Outline of a General Theory of Models, Benjamin, Reading, Massachusetts.

Department of Earth and Space Sciences and

Center for Embedded Networked Sensing

University of California, Los Angeles (UCLA)

Los Angeles, California 90095-1567

Manuscript received 18 November 2004. 